\title{
Falx cerebri Calcifications and Ossifications in CT Scans - A Data Collection on Frequency, Position and Size
}

\author{
Alexander Schedler ${ }^{1}$, MSc; Univ.-Prof. Priv.-Doz. Dr. med. univ. Hannes Deutschmann²
}

\section{Abstract}

Background: The aim of this study is the acquisition of data regarding the frequency, position, size, sex- and age distribution of falx cerebri calcifications (FCC, including ossifications) using CT scans.

Methods: An explorative-retrospective data collection using skull CT scans of all CT devices (in use for patient examinations) at the University Hospital Graz. From August 20 to August $31,2015,365$ cases of undisturbed and non-contrast brain images were determined. FCC with a density threshold value of $>=100 \mathrm{HU}$ was recorded, analysed according to certain target parameters and evaluated using descriptive statistics. Additionally, lateral views of three-dimensional image reconstructions of certain FCC were produced and measured. Also, superior sagittal sinus calcifications were examined.

Results: The occurrence of FCC accounted for $34 \%$ in general and was slightly more frequent in older men. Among all FCC 95\% were located in anterior and medial falx area. The Spearman's rank correlation between age and occurrence of FCC was $r=.96, p<.001$. Considering a sagittal dimension (max. length $x$ max. height $x \sin \left(90^{\circ}\right.$-Gantry Tilt) computed in axial layers) of $>=2 \mathrm{~cm}^{2}$, FCC incidences still amounted to $9,8 \%$.

Conclusions: The FCC frequency of $10 \%$ with a size of $>=2 \mathrm{~cm}^{2}$ (sagittal dimension computed in axial layers) corresponded to values of previous $x$-ray studies. However, the dimension or diameter was never mentioned.

FCC of the size mentioned above is relevant to an osteopath's work since they might influence the craniosacral palpation and treatment of the falx cerebri. Therefore, there is further need for investigation concerning the possible effects of FCC on craniosacral palpation of the falx cerebri, precise measurements of size, as well as a histological comparison alongside CTimaging.

Keywords: Falx cerebri, calcification, ossification, computed tomography

DOI: https://doi.org/10.35740/EJOR.2019.1.1.1 


\section{Background}

Although the falx cerebri is sometimes an important part when it comes to cranial osteopathic examination and treatment, no information can be found on falx cerebri calcifications (FCC, including ossifications) in the relevant osteopathic literature.[1-6] The lack of knowledge about the phenomenon of FCC could possibly lead to difficulties and wrong conclusions regarding the osteopathic diagnosis. Hence, general (German and English) literature about up to date knowledge on FCC was examined.

Previous data on frequency and distribution of FCC are almost exclusively drawn from $\mathrm{x}$-ray studies and vary considerably. An increased frequency of FCC could occasionally be observed in combination with certain clinical pictures, most notably the basal cell nevus-syndrome (70-92\%). $[7,8]$

The projection method of $\mathrm{x}$-ray studies, however, is prone to misinterpretation, if the picture is taken from one direction only. This is the case for $\mathrm{x}$-ray images of FCC because it usually can only be seen in the frontal shot. It is possible to identify radiopaque linear shadows (like FCC) from normal falx cerebri, as Robertson [9] did in 93 out of 100 patients due to various shots per case. Additionally, a large frontal crest might cause similar deceptions. [8] Few studies which also included histological examinations usually described FCC (except for occasional psammoma bodies) as a typical ossification. [10-15]

Concerning the identification of intracranial calcifications, the CT is significantly superior to other imaging methods. [16-19]

Only three CT studies could be found examining FCC frequency. [16, 18, 19] Unfortunately, the data of these studies are not very specific when it comes to frequency, age- and sex distribution.

The present CT-Study has the following research questions:

- How often do FCC and superior sagittal sinus calcifications (SSSC) occur in a diversified sample of patient population?

- How often does FCC occur in a notable size of at least $2 \mathrm{~cm}^{2}$ (this size was chosen because it compares to the size of the smallest European coin, 1 cent)?
- Are there any particularities concerning position, sex- and age distribution, connection to the skull and a noticeable medullary cavity?

- How are FCC displayed in three-dimensional reconstructions?

\section{Methods}

As a basic research, an explorative retrospective data collection was carried out at the Department of Radiology at the University Hospital Graz, Austria.

All four CT devices were used in the study in order to be able to obtain a patient population as broad as possible as it would appear in an osteopath's/therapist's daily work. The CT scans were carried out for clinical reasons and then reviewed in retrospect for this study.

Prior to the study a positive vote from the ethics committee of the Medical University of Graz was obtained (EK-Nr: 27-484 ex 14/15).

\section{Scan parameters (brain) of 4 Multislice Spiral CT Scanners}

(Toshiba Aquilion 64 row, 2006 / Toshiba Aquilion one 320 row, 2008 / Siemens Somatom Definition AS+, 2000 / Siemens Somatom Sensation Cardiac 64, 2004):

Acquisition: Spiral scan mode; $120 \mathrm{kV}$; Pitch 0,55- 0,65, detector configuration $40 \times 0,6 / 32 \mathrm{x}$ 0,5 .

Reconstruction: resulting pixel size $0,47-0,5$ $\mathrm{mm}$; slice thickness 3-5 mm; Increment 2,5-5 $\mathrm{mm}$; soft kernel.

\section{Inclusion criteria}

- Brain window (soft kernel reconstruction to secure proper density measurements)

- Cover of falx cerebri und tentorium cerebelli

- Age between 10 and 99 years

\section{Exclusion criteria}

- Interfering CT-artifacts

- Contrast media

- Tube potential deviating from $120 \mathrm{kV}$ 

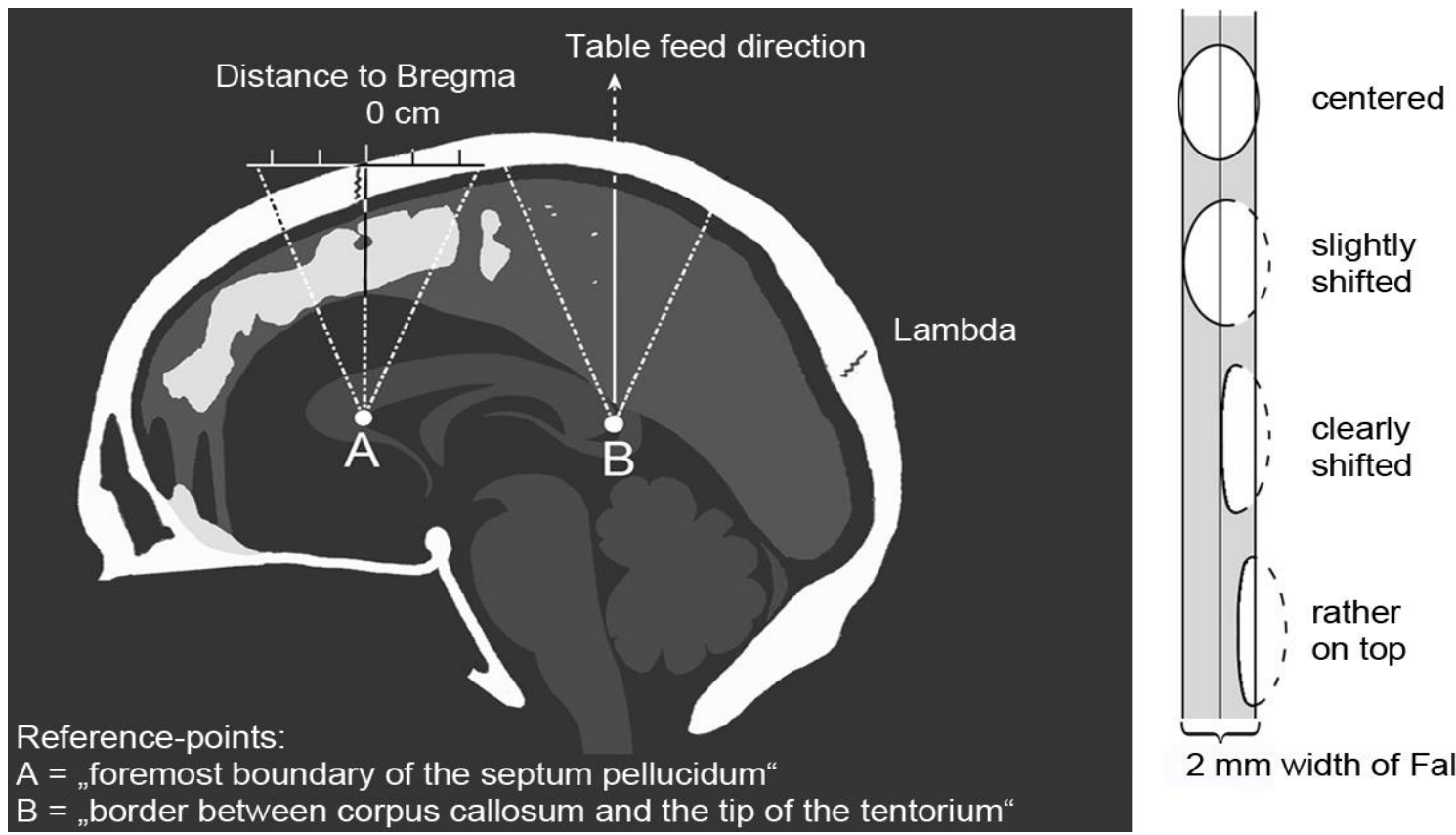

$\mathrm{B}=$ „,border between corpus callosum and the tip of the tentorium

$2 \mathrm{~mm}$ width of Falx

Figure 1. Left: Determination of position along the y-axis with normal course of the parting lines (middle line) and scatter range due to divergent head position (outer dashed line). Right: Determination of position along $\mathrm{x}$-axis.

\section{Exclusion criteria}

- Interfering CT-artifacts

- Contrast media

- Tube potential deviating from $120 \mathrm{kV}$

The sample of 365 patients comprised all brain scans in accordance with the above-mentioned conditions from August 20 to August 31, 2015.

\section{Software and target parameters}

syngo ${ }^{\circledR}$.plaza (VB10A) can create patient lists and was therefore suitable for collecting the raw data:

CT- device; age of patient (10-99 years); sex; presence and number of FCC / SSSC / tentorium cerebelli calcifications (TCC); position (on the $y$ axis), connection to the skull; presence of large frontal crest ( $>=9 \mathrm{~mm}$ depth).

For the largest FCC of each case, the "sagittal dimension of FCC computed in axial layers" was calculated by max. length $\mathrm{x}$ max. height $\mathrm{x}\left(\sin 90^{\circ}\right.$ Gantry Tilt). It can be seen as grey squares/parallelograms in figure 3. Also the FCC-position on $\mathrm{x}$-and $\mathrm{y}$-axis (figure 1) and the presence of medullary cavities were recorded.
The distance measurements were carried out for the density threshold value of $100 \mathrm{HU}$ in a window setting of $c=50 / w=100$.

Based on axial images, the falx could almost be equally divided into anterior, medial and posterior areas to differentiate the FCC position on the $y$ axis (figure 1).

syngo ${ }^{\circledR}$.via was used for three-dimensional image reconstructions of the FCC (figure 3).

Adobe®Photoshop CS2 was applied to the lateral view of $3-D$ reconstructions to calculate the sagittal dimension inside the circumference of FCC (first the isolated FCC was selected from outside with the magic wand tool, then the selection was inverted and the Pixel amount compared to a square of $10 \times 10 \mathrm{~cm}$ ).

\section{Statistics}

Data were evaluated using descriptive statistics. Spearman's rank correlation coefficient was calculated for the relationship between FCC / SSSC and age (significance level of $5 \%$ ). 


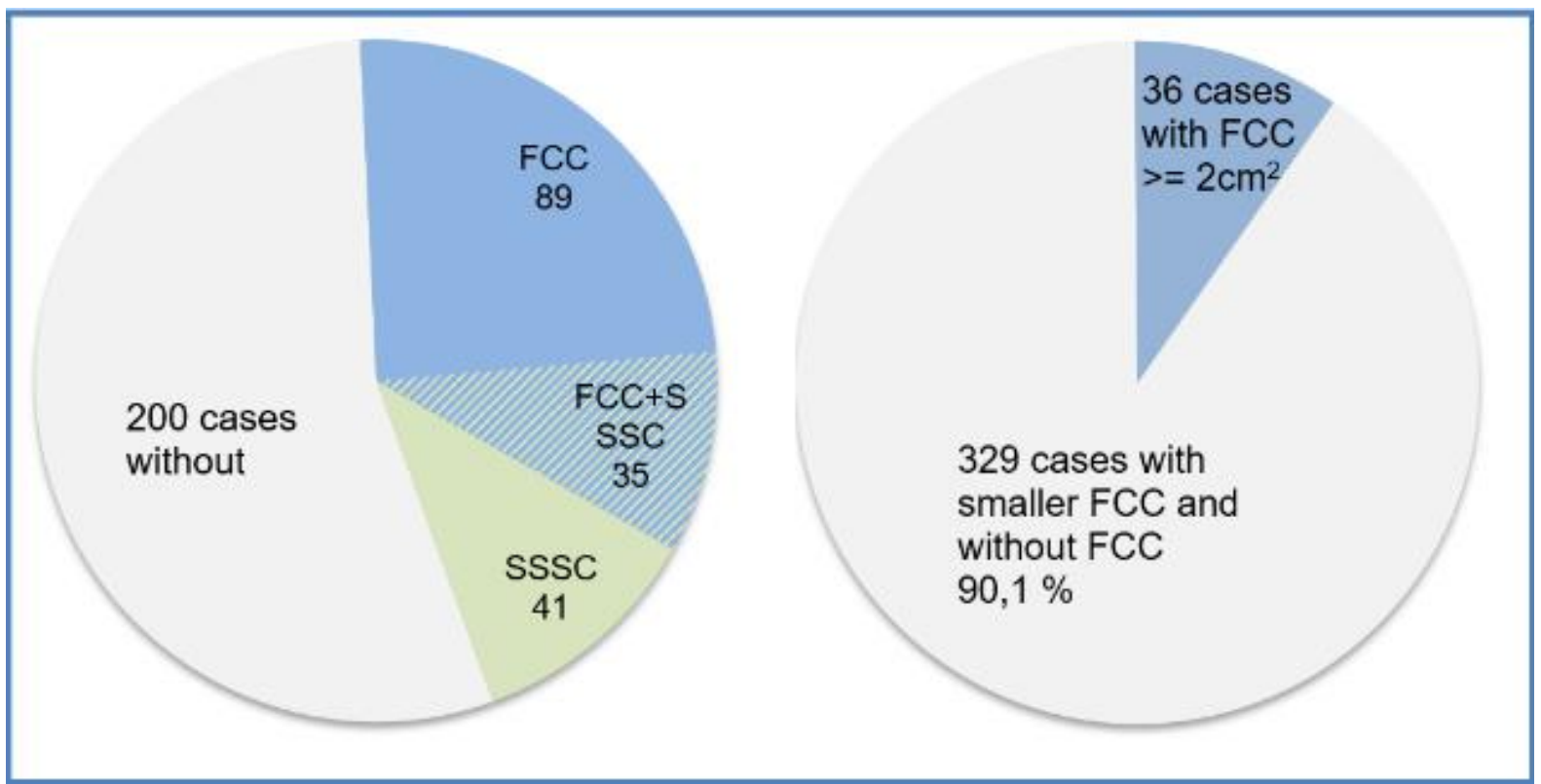

Figure 2. Left: Distribution of FCC and SSSC. Right: Distribution of FCC with a minimal size of $2 \mathrm{~cm} 2$

\section{RESULTS}

FCC were found in 124 cases (34\%, figure 2 , left), of which 36 showed a FCC of at least $2 \mathrm{~cm}^{2}$ $(9,8 \%$, figure 2 , right).

The FCC were located in an anterior position in $45,4 \%$, in medial position in $48,9 \%$ and in a posterior position in $5,8 \%$ of cases. A similar distribution was observed for the biggest FCC of each case.

A highly significant and very strong positive spearman's rank correlation $(r=.96, p<.001)$ could be shown between age and FCC.

FCC-incidence was $37,4 \%$ in men and $31,2 \%$ in women. From the age of 55, however, it rose to $51 \%$ in men compared to only $37,2 \%$ in women. A connection to the skull was only exhibited in 3 cases.

Most FCC showed a medial position along the course of the falx cerebri. In general, starting from a width of $4 \mathrm{~mm}$ a medullary cavity could be identified. On an average, FCC which were broader than the falx cerebri displayed a density comparable to normal bones.

The four largest FCC displayed a continuous sagittal area (the area inside sagittal FCC- outline) between $10-17 \mathrm{~cm}^{2}$ and a width of $0,2-1 \mathrm{~cm}$. Due the smallest FCC were $1 \times 1 \mathrm{~mm}$ on xy-plane and the increment-distance in $z$-direction.
The areas computed in axial layers differ strongly to the areas inside the FCC-outline in lateral views (figure 3).

SSSC incidence was 20,8\%. Compared to FCC it had an opposite distribution of position and no connection could be detected between SSSCfrequency and age $(\mathrm{r}=.02, \mathrm{p}<.04)$.

However, SSSC, for the most part, presented a direct connection to the skull $(64,5 \%)$ and occurred more often in women than men.

Table 1. Frequency of FCC, including the distribution of age and sex of the sample.

\begin{tabular}{|ccccccc|}
\hline Age (Years) & men & FCC & $\%$ & women & FCC & $\%$ \\
\hline $10-19$ & 5 & 0 & 0,0 & 4 & 1 & 25,0 \\
$20-29$ & 11 & 0 & 0,0 & 15 & 3 & 20,0 \\
$30-39$ & 25 & 3 & 12,0 & 14 & 0 & 0,0 \\
$40-49$ & 15 & 3 & 20,0 & 16 & 4 & 25,0 \\
$50-59$ & 26 & 8 & 30,8 & 21 & 3 & 14,3 \\
$60-69$ & 20 & 6 & 30,0 & 25 & 7 & 28,0 \\
$70-79$ & 31 & 17 & 54,8 & 42 & 12 & 28,6 \\
$80-89$ & 27 & 22 & 81,5 & 41 & 19 & 46,3 \\
$90-99$ & 6 & 3 & 50,0 & 21 & 13 & 61,9 \\
\hline Total & 166 & 62 & 37,4 & 199 & 62 & 31,2 \\
\hline
\end{tabular}


TCC were only discovered in 3\% of cases, mostly in combination with FCC and SSSC findings.

In some regions of three-dimensional image reconstructions regularly rounded step edges could be detected. They correspond to the incrementdistance, which is - together with the thickness of a layer - crucial for the image resolution in the z-direction (figure 3, bottom right). Case number 338 (figure 3, top left) displays the largest FCC found, which is marginally connected to the calotte. Case number 195 (figure 3, top right) shows a combination of various FCC sizes. It should be highlighted that only one dural leave of the falx cerebri seems to be affected by the FCC since all FCC are shifted and bulged to one side. The large FCC in case number 358 (figure 3, bottom left) is, for the main part, not wider than the falx cerebri. Only a small area bulges on the side and contains a medullary cavity.

\section{DISCUSSION}

There are several reasons why the findings of this basic research are valuable for osteopaths:

- Knowledge about the frequency and the characteristics of FCC might be essential to allow the correct interpretation of the craniosacral palpated tissue tension quality of the falx cerebri.

- A loss of elasticity caused by FCC could result in limited compensation options of the dural membrane system.

- Novak et al. [20] stated in their single case report that FCC might affect cerebrospinal fluid flow, as suggested by distension of draining vessels compared to healthy volunteers.

- FCC are considered as a physiological phenomenon and not clinically relevant. Only in children, the authors seem to agree on the fact that pathology is the most common cause in case of physiological intracranial calcifications. [19, 21]

However, in past studies with large sample sizes, the frequency of different diseases was only recorded for the group with FCC. Therefore it could not be compared with the FCC-free group. [10, 22-26]

Hence, the disease relevance of FCC seems yet to be unclear, and further studies need to be carried out.
- Data from previous studies on FCC show a considerable degree of inconsistency and low validity.

\section{Data-Discussion- and comparison with previous studies}

Due to improved resolution capacity compared to older CT devices and a superior sensitivity and specificity of CT scans compared to the $\mathrm{x}$-ray method, the frequency of FCC, SSSC and TCC was remarkably higher than previously known. Every third person had a FCC. It seems, however, that only bigger FCC are relevant for the field of osteopathy. As an example we calculated the FCC-frequency for a threshold-size of $2 \mathrm{~cm}^{2}$ - a size comparable to the area of a 1 euro-centcoin (this size is demonstrated in figure 3, top right). We do not know whether this size can be considered relevant or not. However, every tenth patient had a FCC-size of at least $2 \mathrm{~cm}^{2}$. This frequency comes close to what authors of previous (x-ray) studies presented with an average value of $7,8 \%+-6,3$. [10, 16, 21-24, 26-30]

The result of a very strong positive correlation between FCC and age which is statistically very significant is confirmed by all those studies, who presented values that allowed the calculation of the correlation coefficient according to Spearman. $[8,21,24,26,28,30]$

The predominance of anterior (and medial) distribution of FCC corresponds to the opinion of most authors. [11, 13, 17, 19, 24, 29, 31]

Using 178 FCC on medio-sagittal images of x-ray tomography Lanig [24] calculated a 99\% probability that the anterior accumulation of FCC in his sample is not random.

In contrast to observations made by Tsitouridis [13] considerably more cases of multiple FCC occurrences in one patient were discovered (about half of all patients examined). FCC-skull connections, however, were considerably scarce. Siewert [8] interpreted a distinct frontal crest in 12,1\% of his sample. Those, however, were extremely seldom in the present study.

For all remaining results of the present study, no comparable data were found in previous studies. The measurement of the sagittal dimension of FCC in sagittal layers is more suitable regarding 
size determination than the sagittal dimension computed in axial layers.

\section{CONCLUSIONS}

The knowledge about the frequency and characteristics of FCC appears to be important for osteopaths who work in the cranial field. However, the existence of FCC has been ignored in standard osteopathic literature. Data from previous studies on FCC show a considerable degree of inconsistency and low validity. This primary research delivers relevant data about frequency, position, size, sex- and age distribution of FCC.

However, there is a need for further research to support or query the results and to perform a probability calculation of FCC incidence for the normal population.

Following topic areas concerning FCC have been researched little or not at all:

- The question if and which size of an FCC affects the palpatory quality of elasticity of the falx cerebri (reliability studies).

- Examination of FCC characteristics as anatomical preparations (previously identified via CT of corpses).

- For following similar studies including measurements of sagittal FCC dimensions, especially the measurement based on reconstructions in the sagittal plane would be interesting. It offers the most precise value on the actual extent of possible impairments of the falx cerebri.

\section{Discloser}

The authors have no personal financial or institutional interest in any of the drugs, materials or devices described in this article.

\section{Authors' contributions}

AS provided substantial contributions to conception and design, acquisition of data, all analysis and interpretation of data;

HD revised the article critically for relevant intellectual content. Both Authors gave final approval of the version of the article to be published, and all Authors agree to be accountable for all aspects of the work in ensuring that questions related to the accuracy or integrity of any part of the work are appropriately investigated and resolved. In addition, HD provided access to the data archive and organised training by experienced experts for the application tools of syng.plaza and syngo.via to the first author.

\section{Author details}

${ }^{1}$ Danube University Krems, Wiener Schule für Osteopathie, Austria

${ }^{2}$ Medical University Graz, Austria, Department of Radiology

\section{Correspondence}

Alexander Schedler, Physiotherapist and Osteopath, Drosselweg 9, 8076 Vasoldsberg, Austria E-mail: a.schedler@gmx.at

Received: 03 May 2019 Accepted: 24 May 2019 Published: 30 May 2019

\section{REFERENCES}

1. Chaitow L. Cranial Manipulation: Theory and Practice : Osseous and Soft Tissue Approaches. $2^{\text {nd }}$ ed. Edinburgh, Scotland: Elsevier Churchill Livingstone, 2005.

2. Cloet $\mathrm{E}, \mathrm{Gross} \mathrm{B}$, Fuhrmann MC. Osteopathie im kranialen Bereich. $1^{\text {st }}$ ed., Aufl. Stuttgart, Germany: Hippokrates, 1999.

3. Liem L. Kraniosakrale Osteopathie- Ein praktisches Lehrbuch. $5^{\text {th }}$ ed. Stuttgart, Germany: HippokratesVerlag, 2010.

4. Liem T, Eickel V. Praxis der Kraniosakralen Osteopathie: Lehrbuch, $3^{\text {rd }}$ ed. Stuttgart, Germany: Karl F. Haug, 2010.

5. Sills F. Foundations in Craniosacral Biodynamics, Volume Two: The Sentient Embryo, Tissue Intelligence, and Trauma Resolution, $1^{\text {st }}$ ed. Berkeley, California: North Atlantic Books, 2012.

6. Upledger JE, Vredevoogd JD, Klett L. Lehrbuch der CranioSakralen Therapie I, $7^{\text {th }}$ ed. Heidelberg, Germany: Karl F. Haug Verlag; 2016.

7. Lo Muzio L. Nevoid basal cell carcinoma syndrome (Gorlin syndrome). Orphanet J Rare Dis. 2008;3:32. Published online 2008 Nov 25. doi: 10.1186/17501172-3-32.

8. Siewert B. Die Verkalkung der Falx cerebri als pathognomonisches Zeichen beim Gorlin-Goltz-Syndrom 
[dissertation]. Kiel, Germany: Kiel University; 1989. http://www.clinicasomosaguas.com/multimedia/Doktorarbeit_Siewert.pdf. Accessed March 01, 2015.

9. Robertson $\mathrm{G}$. The roentgenographic appearence of the falx cerebri. Radiology. 1946;56:320-323. doi:10.1016/0037-198X(74)90030-3

10. Heidrich R, Küstner R. Über Falxverkalkungen. Fortschr Roentgenstr. 1967;107:402-405. doi: 10.1055/s0029-1228230

11. Batnitzky S, Powers JM, Schechter MM. Falx 'calcification'--does this exist?. Neuroradiology. 1974; 7(5):255-260. doi:10.1007/BF00344244

12. Rao SR, Rao TR, Ovchinnikow N, McRae A, Rao AVC. Unusual isolated ossification of falx cerebri: a case report. Neuroanatomy. 2007;8:54-55. http://www.neuroanatomy.org/2007/054_055.pdf. Accessed March 01, 2015.

13. Tsitouridis I, Natsis K, Goutsaridou F et al. Falx Cerebri Ossification: CT and MRI Evaluation. Neuroradiol J. 2006;19(5):621-628. http://neu.sagepub.com/content/19/5/621.full.pdf+html. Accessed March 01, 2015.

14. Tubbs RS, Kelly DR, Lott R, Salter EG, Oakes WJ. Complete ossification of the human falx cerebri. Clin Anat. 2006;9(2):147-150. doi: 10.1002/ca.20162.

15. Zandian A, Clarke P, Tubbs RS, Loukas M. A partially ossified falx cerebri. Folia Morphol.,2014;73(3):363365. doi: 10.5603/fm.2014.0053.

16. Becker H, Grau H, Hacker, H. Endokranielle Verkalkungen in der Computer-Tomographie - Ein Vergleich zum Röntgenbild. Fortschr Roentgenstr.1977;126(6):509-512. doi: 10.1055/s-00291230628

17. Becker H. Intrakranielle Verkalkungen im Computertomogramm [dissertation]. Frankfurt, Germany: Goethe University, Department of Human Medicine, Germany; 1981.

18. Daghighi MH, Rezaei V, Zarrintan S, Pourfathi H. Intracranial physiological calcifications in adults on computed tomography in Tabriz, Iran. Folia Morphol., 2007;66(2):115-119. https://journals.viamedica.pl/folia_morphologica/article/view/16037/12675. Accessed March 01, 2015.

19. Uduma FU, Pius F, Mathieu M. Computed tomographic pattern of physiological intracranial calcifications in a city in central Africa. Glob J Health Sci. 2012;4(1):184-191. doi:10.5539/gjhs.v4n1p184

20. Bruch G, Bushe KA, Gregl A. Die nicht-pathologischen intrakraniellen Verkalkungen. Fortschr Roentgenstr. 1965;103(10):444-449. doi: 10.1055/s-00291227771

21. Bruyn GW. Calcification and ossification of the cerebral falx and superior longitudinal sinus. Psychiatr Neurol Neurochir.1963;66:98-119.
22. Dyke CG. Indirekt signs of brain tumor as noted in routine roentgen examinations. Am J Roentgenol. 1930;23:598-606.

23. Hauser KP. Über die Bedeutung von Verkalkungen der Falx cerebri bei neurochirurgisch-neurologischen Kranken [dissertation]. Berlin, Germany: Faculty of Medicine, Free University of Berlin; 1968.

24. Lanig M. Untersuchung über die Falxverkalkung anhand der mediosagittalen Schichtaufnahme des Schädels [dissertation]. Würzburg, Germany: University Würzburg, Department of Medicine; 1976.

25. Parnitzke KH. Falxverkalkungen in Klinik und Röntgenbild- Kritische Bearbeitung von 363 Verkalkungen. Dtsch Z Nervenheilkd. 1948;59:81-96. doi: 10.1007/BF00213149

26. Parnitzke KH. Endokranielle Verkalkungen im Röntgenbild, ihre Deutung und Bedeutung im Dienste der klinischen Hirndiagnostik. Leipzig, Germany: Georg Thieme; 1961.

27. Seuffer R. Vergleichende Untersuchungen zur Häufigkeit der Verkalkung der Falx cerebri im Röntgenbild. Thübingen, Germany: Fotodruck Präzis; 1969.

28. Ojuawo A, Nzeh AA, Salisu A. Calcification of falx cerebri: a normal variant or a pathological entity?. Sahel Med. J. 2003;6(2):40-43. doi: http://dx.doi.org/10.4314/smj2.v6i2.12833

29. Kieffer SA Gold LHA. Intracranial physiologic calcifications. Semin Roentgenol. 1974;9(2):151-162. doi: http://dx.doi.org/10.1016/0037-198x(74)90030-3 